\title{
Development of a Surface Roughness Prediction Model for Slow Tool Servo Turning Machining
}

Wei Zhou (0000-0001-5233-908X), Min Kang (0000-0001-6864-7802), Hangyan Guo (0000-0002-4364-4004) College of Engineering, Nanjing Agricultural University, No. 40, Dianjiangtai Road, Pukou Distinct, Nanjing 210031.China. Email: 1506036510@qq.com, kangmin@njau.edu.cn,2019112003@njau.edu.cn

To investigate the effect of slow tool servo turning process parameters on surface roughness, we established a high precision surface roughness prediction model. A guide to the selection of turning process parameters was compiled, and a turning test was conducted based on a response surface method (RSM) central composite design. ANOVA explores the influence law of process parameters on surface roughness. A RSM BP neural network model, and MEA-BP surface roughness model were established and the prediction performance of the three models was evaluated. The results show that the significant process parameters affecting surface roughness are tool radius, discrete angle, feed rate, and cutting depth in descending order; and the prediction errors of RSM, BP, and MEA-BP are $11.41 \%, 19.67 \%$, and $5.54 \%$. This suggests that the MEA-BP model has the highest prediction accuracy with the same test data, RSM is second, whilst the single BP model struggles to capture multiple data characteristics and its prediction accuracy is poor. In addition, MEA can effectively solve the BP model falling into local optimum and improve the model prediction accuracy.

Keywords: Process parameters, Surface roughness, Response surface method, BP neural network, Mind evolutionary algorithm

\section{Introduction}

Complex optical surface components play an increasingly important role in optics, medicine, and defense, owing to their excellent optical properties [1-4]. Slow tool servo turning technology can achieve repeated machining of complex optical surface components with submicron or higher surface accuracy, nanometer surface roughness without treatment after machining, and high machining efficiency. It provides a new way to accurately machine complex optical surfaces with high efficiency [5-7].

Surface roughness affects the optical properties of curved components and is influenced by several factors such as cutting form and uneven cutting parameters. Scholars have devoted themselves to investigating the relationship between surface roughness and process parameters in order to establish a conditionspecific surface roughness predictive model to guide the selection of machining parameters. Lin Y. C. et al. [8] used RSM to analyze the effects of spindle speed and cutting depth on surface roughness during cutting, and established a BP neural network model of surface roughness based on spindle speed, cutting depth, and feed rate. Alajmi M. S. et al. [9] combined an artificial neural network, fuzzy algorithm, and evolutionary algorithm to establish a prediction model using the ANFIS-QPSO machine learning method to improve the prediction accuracy of surface roughness of AISI 304 stainless steel after dry turning. Chen C. et al. [10] studied the influence law of process parameters on surface roughness through orthogonal tests and established a multivariate composite prediction model of surface roughness based on a simulated annealing algorithm with a prediction accuracy of more than $95 \%$. The model provides theoretical guidance for establishing a surface roughness prediction model for complex surface turning machining. Lu J. et al. [11] established a surface roughness prediction model based on PSO-SVM, PSO-BP, and PSO-SVM+PSO$\mathrm{BP}$ for milling creeping graphite cast iron, which proved that prediction models optimized by multiple algorithms often have a better prediction performance, but prediction models established by the fusion of multiple algorithms are more complicated and the prediction takes longer.

Currently, research on surface roughness prediction technology mainly focuses on traditional milling, cutting, and other fields, and research cases on slow tool servo turning technology are rare. Also, due to the superiority of RSM in exploring the interaction between independent variables and response values, and the excellent prediction fitting ability of the artificial neural network, this paper investigates the effect of turning process parameters on surface roughness by response surface test. It also establishes a RSM and BP neural network surface roughness prediction model based on test data and optimizes the BP model via a mind evolutionary algorithm to improve the model prediction accuracy. 


\section{Test equipment and methods}

\subsection{Equipment and materials}

Figure 1 shows the laboratory self-developed slow tool servo CNC machine tool, which includes two linear axes; $\mathrm{X}$-axis and $\mathrm{Z}$-axis, and a rotary axis; $\mathrm{C}$-axis. The slow tool servo turning machine tool drives the diamond tool relative to the workpiece end face in the cylindrical coordinate system through $\mathrm{C}, \mathrm{X}$, and Zaxes linkage to achieve a spiral trajectory cutting motion to realize the machining of complex surfaces [12]. The test machining material is polymethyl methacrylate (PMMA), the cutting tool is the polycrystalline diamond (PCD), the front angle of the tool is $0^{\circ}$, and the back angle is $10^{\circ}$, and the cutting condition is dry cutting.

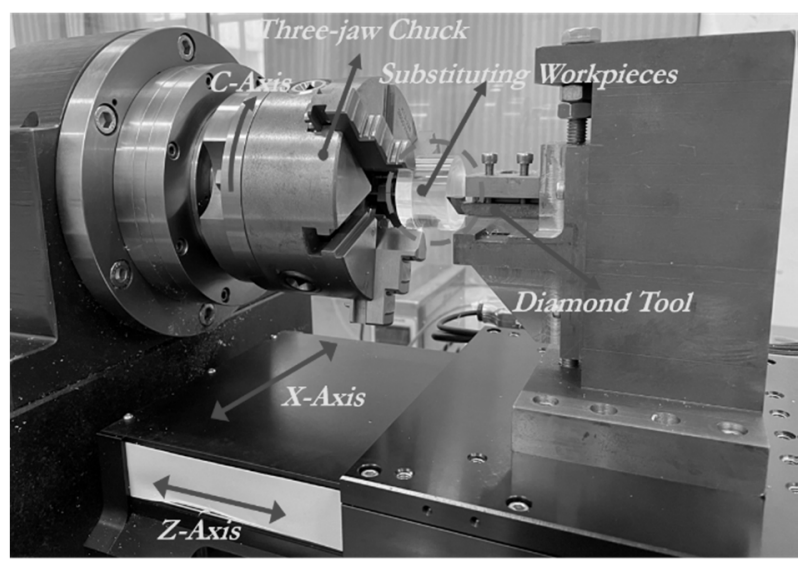

Fig. 1 Slow tool servo turning stage

\subsection{Slow tool servo turning method}

In slow tool servo turning the point where the tool edge is at a tangent to the machined surface is called the cutting contact point (CCP). Since the CCP can be any point on the tool edge during cutting, it is necessary to specify a fixed point on the tool to determine the position of the tool in the cutting process, which is called the cutting location point (CLP) [13]. The tool trajectory in slow tool servo turning machining should be consistent with the CLPs. Obtaining the CLPs from the CCPs by a compensation algorithm is crucial for achieving complex surface machining using slow tool servo turning technology. The process is shown in Figure 2. The discrete CCP is compensated according to the tool shape and surface characteristics, to obtain the CLP. The tool moves along the intercept line to the corresponding CLP to finish the machining of complex surfaces. In Figure 2, P is the CCP; CC is the intersection line between the workpiece and the cutting plane; $n$ is the normal vector of the surface at P; $n_{p}$ is the projection of the normal vector on the cutting plane; $t_{p}$ is the tangential vector of $\mathrm{P}$ at the intersection line CC.

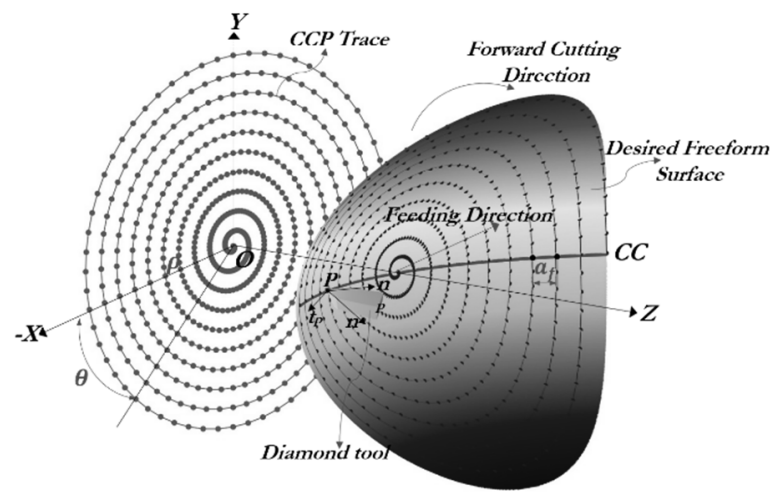

Fig. 2 Diagram of tool compensation

The most commonly used CCP trajectory planning approaches are equal parameter, section, spacing, and residual height methods $[14,15]$. If $\mathrm{C}$-axis is the rotation axis and the workpiece to be machined is mostly a circular body, the equal section method is selected for the path planning, with the spiral column surface as the constraint surface $[16,17]$. The slow tool servo turning $\mathrm{CNC}$ system can only manage the motion between specified points, so the tool contact trajectory must be discretized according to the corresponding rules. The standard methods for tool contact trajectory discretization are equal angles discretization and equal arc length discretization. Tool compensation solves the correct position point, and compensation, before determining the tool parameters. Involved general tool compensation parameters include the tool radius, tool back angle, and tool front angle. Comprehensive analysis shows that the parameters involved in slow tool servo turning of the machine are mainly tool radius, tool back angle, tool front angle, discrete angle, and discrete arc length, etc. The processing parameters can be determined according to the actual situation to complete the processing of complex surface components.

\subsection{Response surface test design}

This experiment selected the central composite method in Design-Expert software to develop a 4-factor, 5-level test protocol. The factor coding levels are shown in Table 1 . The values of each level were set from literature [18] and previous research results. The effect of tool radius $\left(R_{t}\right)$, feed rate $\left(a_{f}\right)$, cutting depth $\left(a_{p}\right)$, and dispersion angle $(\Delta \theta)$ on surface roughness was examined in the test. Design-Expert software was used to design the test with the center point and axis values set to 2 , and a total of 26 sets of test protocols were obtained. 
Tab. 1 Table of response surface experimental factor levels

\begin{tabular}{|c|c|c|c|c|c|c|}
\hline \multirow{2}{*}{ Factor } & \multirow{2}{*}{ Code } & \multicolumn{5}{|c|}{ Level } \\
\hline & & -2 & -1 & 0 & 1 & 2 \\
\hline$\overline{R_{t} /(\mathrm{mm})}$ & $\mathrm{X}_{1}$ & 0.25 & 0.50 & 0.75 & 1.00 & 1.25 \\
\hline$a_{f} /(\mathrm{mm} / \mathrm{r})$ & $\mathrm{X}_{2}$ & 0.01 & 0.02 & 0.03 & 0.04 & 0.05 \\
\hline$a_{p} /(\mathrm{mm})$ & $\mathrm{X}_{3}$ & 0.01 & 0.02 & 0.03 & 0.04 & 0.05 \\
\hline$\Delta \theta /\left(^{\circ}\right)$ & $X_{4}$ & 2 & 4 & 6 & 8 & 10 \\
\hline
\end{tabular}

\subsection{Response surface prediction model construc- tion}

Surface roughness is affected by the interaction of multiple process parameters, and the prediction model is nonlinear. Referring to the literature [19, 20], this paper chose the second-order response surface method to fit the relationship between each parameter and response value. The fitting equation is shown in equation (1).

$$
Y=\beta_{0}+\sum_{\mathrm{i}=1}^{\mathrm{k}} \beta_{\mathrm{i}} \mathrm{X}_{\mathrm{i}}+\sum_{\mathrm{i}=1}^{\mathrm{k}} \beta_{\mathrm{ii}} \mathrm{X}_{\mathrm{i}}^{2}+\sum_{\mathrm{i}=1}^{\mathrm{k}-1} \sum_{\mathrm{j}=2}^{\mathrm{k}} \beta_{\mathrm{ij}} \mathrm{X}_{\mathrm{i}} \mathrm{X}_{\mathrm{j}}+\varepsilon
$$

Where:

$\beta_{0} \ldots$ Constant term,

$\beta_{i}, \beta_{i i}, \beta_{i j} \ldots$ Regression coefficients of the interaction terms,

$\varepsilon$...Error term.

\subsection{Neural network prediction model construc- tion}

This paper uses a three-layer BP neural network (input, hidden, and output layer) to create a surface roughness prediction model. The tool radius, feed rate, cutting depth, and discrete angle are used as input layer parameters, and the surface roughness is the output layer parameters. There is no standard setting rule for the number of hidden layers, so we referred to the empirical formula (2) for the setting. The sigmoid function was chosen as the activation function for the hidden layer. The network learning rate was set to 0.01 , the maximum number of iterations was set to 1000 , and the Pearson coefficient was chosen to reflect the correlation between the actual and desired output.

$$
\mathrm{L}_{\text {hid }}=\sqrt{\mathrm{L}_{\text {in }}+\mathrm{L}_{\text {out }}}+\mathrm{r}, \mathrm{r}=1 、 2 、 \ldots, 10
$$

Where:

Lbid...Number of nodes in the hidden layer,

Lin...Number of nodes in the input layer,

$L_{\text {out }} . .$. Number of nodes in the output layer.

\subsection{MEA-BP prediction model building}

The core of the BP neural network algorithm is a gradient descent method, an optimization algorithm that easily falls into the local optimum. Since the surface roughness data sequence generated in slow tool servo machine turning contains linear, nonlinear, and other, features, it is difficult for a single BP prediction model to capture multiple data features, resulting in poor prediction results. Therefore, in this paper, we chose the MEA with vital global optimization seeking ability, relatively few parameters to be tuned, and fast convergence speed, to optimize the initial weights and thresholds of the BP neural network. It can accelerate the convergence speed of the BP neural network, avoid falling into local extremes and improve the prediction accuracy [21, 22].

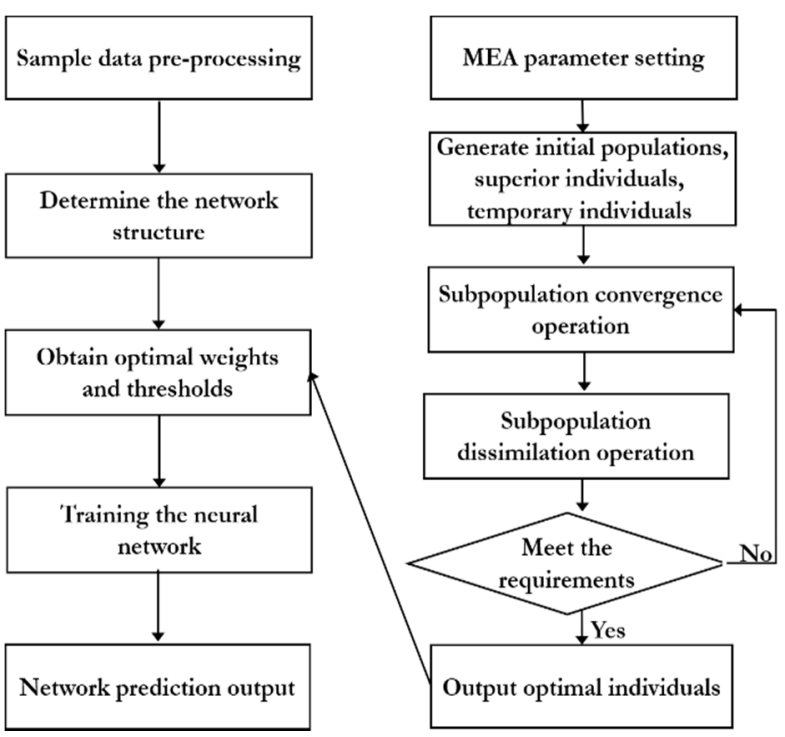

Fig. $3 \mathrm{ME}$ A optimized BP neural network structure diagram

The MEA uses some of the basic concepts of genetic algorithms, such as "population" and "individual," but there some new concepts have been added to MEA compared to GA [23, 24]:

(1) Population and subpopulation: The set of all individuals in each generation of the evolutionary process is called a population, and a population can be divided into several subpopulations. Subpopulations include the superior subpopulation and the temporary subpopulation. The superior subpopulation is used to record competition winners, whilst the temporary subpopulation is used to record the global competition process.

(2) Bulletin board: The bulletin board is mainly used to record subpopulation serial numbers, actions, and scores. The subpopulation number is used to distinguish different individuals, and the description of 
the action varies depending on the application area. For example, when applying the MEA to study parameter optimization problems, the action is the description of the specific position of the individual, and the score is the evaluation of the individual action by the environment. The subpopulation number, action, and score are used to quickly obtain the optimal individual.

(3) Convergence and dissimilation: The process by which individuals in a subpopulation compete is called convergence. In the convergence process, if no winner is produced in the subpopulation, the convergence is over, and the subpopulation has matured. The process of subpopulations competing to win in the whole solution space is called alienation. The alienation process is specified as follows: when the temporary subpopulation scores higher than the superior subpopulation, the temporary subpopulation will replace the superior subpopulation, and the replaced superior subpopulation will be released, and then the released individuals will once again search in the global scope to form a new temporary subpopulation.

\section{Results and analysis}

\subsection{Response surface method test results}

This test uses a JB-4C type contact surface roughness measuring instrument to measure the workpiece surface roughness. As shown in Figure 4, the roughness of the surface was measured at eight places at equal angles, and the maximum and minimum values of the measurement results were removed. The obtained average value was deemed as the surface roughness value. The test results are shown in Table 2.

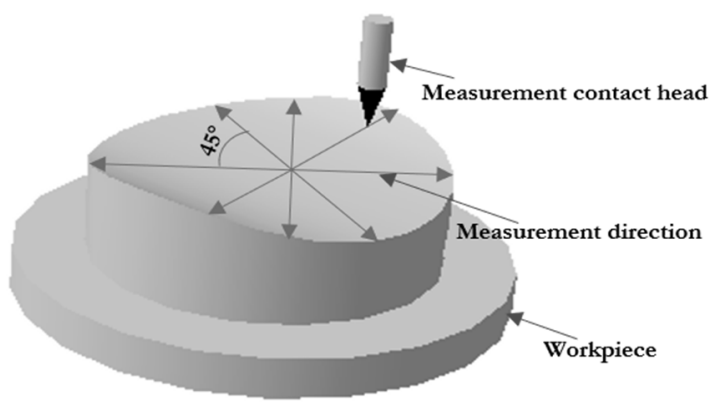

Fig. 4 Schematic diagram of surface roughness measurement

Tab. 2 Response surface method test results

\begin{tabular}{cccccc}
\hline $\begin{array}{c}\text { Test nu- } \\
\text { mber }\end{array}$ & $\begin{array}{c}\text { Tool radius } \\
R_{t} /(\mathrm{mm})\end{array}$ & $\begin{array}{c}\text { Feed rate } \\
a_{f} /(\mathrm{mm} / \mathrm{r})\end{array}$ & $\begin{array}{c}\text { Cutting depth } \\
a_{p} /(\mathrm{mm})\end{array}$ & $\begin{array}{c}\text { Divergence angle } \\
\Delta \theta /()^{\circ}\end{array}$ & $\begin{array}{c}\text { Surface roughness } \\
\mathrm{R} a /(\mu \mathrm{m})\end{array}$ \\
\hline 1 & 0.50 & 0.04 & 0.04 & 8 & 0.1222 \\
2 & 0.75 & 0.05 & 0.03 & 6 & 0.1053 \\
3 & 1.00 & 0.04 & 0.02 & 6 & 0.0950 \\
4 & 0.75 & 0.03 & 0.01 & 8 & 0.0727 \\
5 & 0.50 & 0.02 & 0.02 & 8 & 0.0872 \\
6 & 1.00 & 0.02 & 0.02 & 4 & 0.0743 \\
7 & 1.00 & 0.02 & 0.02 & 2 & 0.0725 \\
8 & 0.75 & 0.03 & 0.03 & 6 & 0.0805 \\
9 & 0.25 & 0.03 & 0.03 & 4 & 0.1067 \\
10 & 0.50 & 0.04 & 0.02 & 6 & 0.0722 \\
11 & 0.75 & 0.03 & 0.03 & 4 & 0.0920 \\
12 & 0.50 & 0.02 & 0.02 & 8 & 0.0680 \\
13 & 1.00 & 0.02 & 0.04 & 6 & 0.0540 \\
14 & 0.75 & 0.01 & 0.03 & 8 & 0.0952 \\
15 & 0.50 & 0.02 & 0.04 & 6 & 0.0710 \\
16 & 0.75 & 0.03 & 0.05 & 6 & 0.1180 \\
17 & 1.25 & 0.03 & 0.03 & 8 & 0.1137 \\
18 & 0.50 & 0.04 & 0.02 & 4 & 0.1102 \\
19 & 0.50 & 0.04 & 0.04 & 4 & 0.0982 \\
20 & 1.00 & 0.04 & 0.04 & 10 & 0.0743 \\
21 & 0.75 & 0.03 & 0.03 & 4 & 0.1038 \\
22 & 0.50 & 0.02 & 0.04 & 8 & 0.0900 \\
23 & 1.00 & 0.04 & 0.04 & 4 & 0.0683 \\
24 & 1.00 & 0.04 & 0.02 & 4 & 0.0685 \\
25 & 1.00 & 0.02 & 0.04 & 6 & \\
26 & 0.75 & 0.03 & 0.03 & & \\
\hline
\end{tabular}

The regression equation analysis of the experimental data was performed by Design-Exper software. With the tool radius $\left(\mathrm{X}_{1}\right)$, feed rate $\left(\mathrm{X}_{2}\right)$, cutting depth $\left(\mathrm{X}_{3}\right)$, and dispersion angle $\left(\mathrm{X}_{4}\right)$ as independent variables and surface roughness $(\mathrm{Y})$ as the response value, the response surface quadratic regression equation was fitted as: 


$$
\begin{aligned}
\mathrm{Ra}= & 0.313-0.476 \mathrm{X}_{1}-2.207 \mathrm{X}_{2}-0.255 \mathrm{X}_{3}-0.011 \mathrm{X}_{4}+0.783 \mathrm{X}_{1} \mathrm{X}_{2}-0.583 \mathrm{X}_{1} \mathrm{X}_{3} \\
& +0.001 \mathrm{X}_{1} \mathrm{X}_{4}+13.563 \mathrm{X}_{2} \mathrm{X}_{3}+0.136 \mathrm{X}_{2} \mathrm{X}_{4}+0.005 \mathrm{X}_{3} \mathrm{X}_{4} \\
& +0.282 \mathrm{X}_{1}^{2}+26.281 \mathrm{X}_{2}^{2}+6.781 \mathrm{X}_{3}^{2}+0.0005 \mathrm{X}_{4}^{2}
\end{aligned}
$$

\subsection{Analysis of variance}

ANOVA allows the selection and ranking of nonsignificant influences and determines the importance of each process parameter and its interaction on the response. In ANOVA, $\mathrm{P}<0.05$ corresponds to a significant factor effect, and $\mathrm{P}<0.01$ corresponds to a highly significant effect [25]. In Table 3 , the F-value of the model is $40.45, \mathrm{P}<0.0001$, indicating that the regression model is highly significant; the F-value in the misfit test term of the model is $3.65, \mathrm{P}>0.1$, indicating that the regression model is not significantly misfit; the signal-to-noise ratio of the model is 28.352 , which indicates that the model can be used for prediction when the signal-to-noise ratio is greater than 4 [26]; $\mathrm{R}^{2}=0.9809$ and adjusted $\mathrm{R}^{2}=0.9567$. The two values are similar and close to 1 , indicating that the model fits well and has high confidence. Three of the four factors were significant influences, in descending order of significance; tool radius $\left(\mathrm{X}_{1}\right)$, dispersion angle $\left(\mathrm{X}_{4}\right)$, feed rate $\left(\mathrm{X}_{2}\right)$, and cutting depth $\left(\mathrm{X}_{3}\right)$.

Tab. 3 Response surface model analysis of variance table

\begin{tabular}{ccccccc}
\hline Source & $\begin{array}{c}\text { Sum of squ- } \\
\text { ares }\end{array}$ & df & Mean square & F-value & p-value & Significance \\
\hline Model & 0.013 & 14 & $9.431 \times 10^{-4}$ & 40.450 & $<0.0001$ & highly significant \\
$X_{1}$ & $3.750 \times 10^{-3}$ & 1 & $3.750 \times 10^{-3}$ & 160.200 & $<0.0001$ & highly significant \\
$X_{2}$ & $1.284 \times 10^{-4}$ & 1 & $1.284 \times 10^{-4}$ & 5.510 & 0.0387 & significant \\
$X_{3}$ & $1.175 \times 10^{-6}$ & 1 & $1.175 \times 10^{-6}$ & 0.074 & 0.7913 & \\
$X_{4}$ & $1.295 \times 10^{-4}$ & 1 & $1.295 \times 10^{-4}$ & 5.550 & 0.0380 & significant \\
$X_{1} X_{2}$ & $6.123 \times 10^{-5}$ & 1 & $6.123 \times 10^{-5}$ & 2.630 & 0.1334 & \\
$X_{1} X_{3}$ & $3.393 \times 10^{-5}$ & 1 & $3.393 \times 10^{-5}$ & 1.460 & 0.2530 & \\
$X_{1} X_{4}$ & $4.516 \times 10^{-6}$ & 1 & $4.516 \times 10^{-6}$ & 0.190 & 0.6684 & \\
$X_{2} X_{3}$ & $2.943 \times 10^{-5}$ & 1 & $2.943 \times 10^{-5}$ & 1.260 & 0.2851 & \\
$X_{2} X_{4}$ & $1.183 \times 10^{-4}$ & 1 & $1.183 \times 10^{-4}$ & 5.070 & 0.0457 & significant \\
$X_{3} X_{4}$ & $1.806 \times 10^{-7}$ & 1 & $1.806 \times 10^{-7}$ & $7.747 \times 10^{-3}$ & 0.9314 & \\
$X_{1}^{2}$ & $5.416 \times 10^{-3}$ & 1 & $5.416 \times 10^{-3}$ & 232.300 & $<0.0001$ & highly significant \\
$X_{2}^{2}$ & $1.206 \times 10^{-4}$ & 1 & $1.206 \times 10^{-4}$ & 5.170 & 0.0440 & significant \\
$X_{3}^{2}$ & $8.027 \times 10^{-6}$ & 1 & $8.027 \times 10^{-6}$ & 0.340 & 0.5692 & \\
$X_{4}^{2}$ & $7.448 \times 10^{-5}$ & 1 & $7.448 \times 10^{-5}$ & 3.190 & 0.1015 & \\
Residual & $2.565 \times 10^{-4}$ & 11 & $2.332 \times 10^{-5}$ & - & - & - \\
Lack of fit & $2.496 \times 10^{-4}$ & 10 & $2.565 \times 10^{-5}$ & 3.650 & 0.3881 & not significant \\
Pure Error & $6.845 \times 10^{-6}$ & 1 & $6.845 \times 10^{-6}$ & - & - & - \\
Cor Total & 0.013 & 25 & - & - & - & - \\
\hline $\mathrm{R}^{2}=0.9809$ & & & & & & - \\
Adj R $\mathrm{R}^{2}=0.9567$ & & & & & \\
Adeq Precision $=28.3520$ & & & & & \\
\hline
\end{tabular}

\subsection{Response surface analysis of surface rough- ness}

The response surface method is used to analyze the degree of interaction effects on surface roughness, observe the strength of the interaction term effects and capture the trend of the effect of each parameter. As shown in Figure 5, each graph indicates the influence of the remaining two variables on the surface roughness when any two variables from tool radius $\left(R_{t}\right)$, feed rate $\left(a_{f}\right)$, cutting depth $\left(a_{p}\right)$, and dispersion angle $(\Delta \theta)$ are located at the middle level. Theoretically, if the surface slope is extensive, the interaction between the parameters significantly affects the response value. 

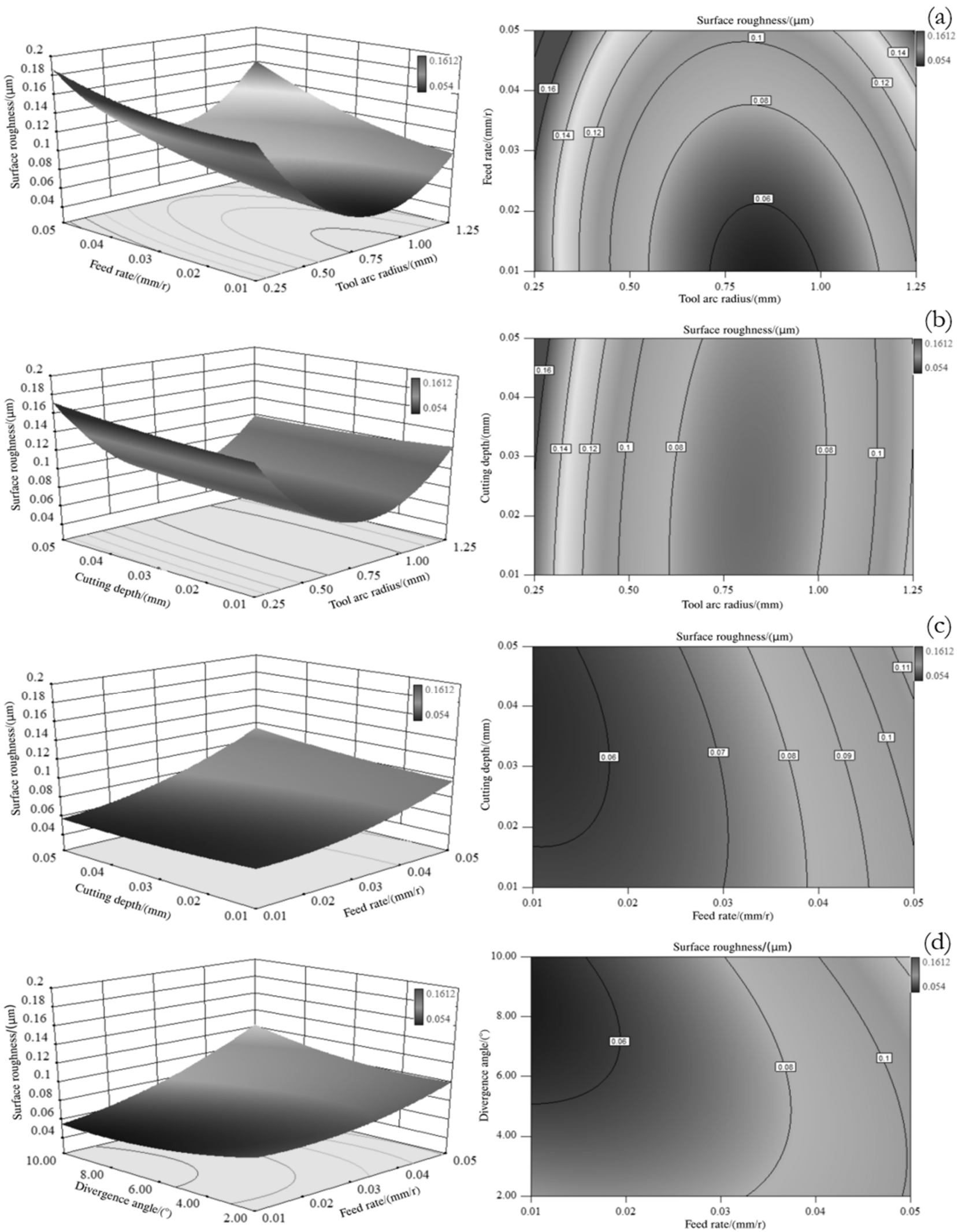

(a) Response surface and contour plot of surface roughness under the interaction of tool radius and feed rate

(b) Response surface and contour plot of surface roughness for the interaction of tool radius and cutting depth

(c) Response surface and contour plot of surface roughness for the interaction of feed rate and cutting depth

(d) Response surface and contour plot of surface roughness for the interaction between feed rate and discrete angle

Fig. 5 Response surface and contour plot of surface roughness under the interaction between factors 
As shown in Figure 5(a), with a specific feed rate, the surface roughness will show a trend of decreasing and subsequently increasing with an increase in tool radius. The influence of the tool radius on surface roughness is more significant with a low feed rate. This is because when the tool radius is within a specific range, the actual theoretical surface roughness trend remain the same, where the theoretical surface roughness value can be derived from the formula $\mathrm{Ra}=a_{\mathrm{f}}^{2} / 8 \mathrm{R}_{\mathrm{t}}$. However, when the tool radius is larger, the contact area between the cutting edge and the surface of the workpiece increases, the friction becomes more extensive, and the squeezing effect increases. Simultaneously, the residual stress at the machining surface increases, and the surface roughness also begins to increase. From Figure 5(b), it can be seen that surface roughness is significantly affected by tool radius, but with a specific tool radius, the surface roughness will slowly increase with increases in cutting depth. The reason for this is that in the effective cutting depth range, cutting depth will intensify the extrusion between the tool edge and the workpiece. Consequently, the friction becomes more extensive, resulting in an increase in cutting force, which impacts the surface roughness. From Figure 5(c), it can be seen that surface roughness is more significantly affected by feed rate, and the two increase simultaneously when the cutting depth is specified. The reason is that as the feed rate increases, the cutting volume per unit time and the friction between the tool edge and the workpiece increase, augmenting the cutting heat, and resulting in a decline in surface quality, and an inevitable increase in surface roughness. From Figure 5(d), it can be seen that the slope of the 3D response surface plot is more extensive, which indicates that the interaction between feed rate and discrete angle has a more significant effect on surface roughness, which is consistent with the ANOVA results. When the feed rate is specific, the surface roughness shows a trend of decreasing and then increasing with increases in the dispersion angle. This is because when the dispersion angle is small, the number of generated tool points is high, and the cutting volume per unit time is relatively high. The friction between the tool edge and the workpiece increases, the cutting heat increases, and the surface roughness increases. When the dispersion angle is large, the tool position points far away from the center of the workpiece are too scattered so it is difficult for the tool blade to remove all the material from the workpiece surface in one machining, causing the surface roughness to increase.

Using the Optimization module of the Design-Exper software to limit the value range of surface roughness optimization to $0.03 \sim 0.06 \mu \mathrm{m}$, the optimal solution within the parameter range was obtained as follows: tool radius $0.86 \mathrm{~mm}$; feed rate $0.01 \mathrm{~mm} / \mathrm{r}$; cutting depth $0.04 \mathrm{~mm}$; and discrete angle $8.3^{\circ}$. However, the tool compensation algorithm selects the equal angle discrete method to generate the $\mathrm{CNC}$ machining code, which must ensure that $\mathrm{n}=360^{\circ} / \Delta \theta$ is a positive integer, and the dispersion angle needs to be adjusted to $8^{\circ}$. The RSM surface roughness prediction is $0.051 \mu \mathrm{m}$ under this parameter, and the actual surface roughness under this condition is $0.057 \mu \mathrm{m}$ with a relative error of $11.76 \%$. In this paper, to test the predictive generalization ability of the response surface model, another five sets of parameters were randomly set for the test (not repeated within the 26 sets of tests). The results are shown in Table 4, and it can be seen that the actual values correspond well with the predicted values, and the relative error is around $10 \%$, with an average relative error of $11.41 \%$. The data indicates that although the prediction performance of the RSM model has a certain degree of feasibility, its prediction accuracy needs to be improved.

Tab. 4 Prediction results of RSM

\begin{tabular}{|c|c|c|c|c|c|c|c|c|}
\hline \multirow{2}{*}{ serial } & \multicolumn{4}{|c|}{ parameter } & \multirow{2}{*}{$\begin{array}{c}\text { predictive } \\
\text { value/( } \mu \mathrm{m})\end{array}$} & \multirow{2}{*}{$\begin{array}{l}\text { real va- } \\
\text { lue/( } \mu \mathrm{m})\end{array}$} & \multirow{2}{*}{$\begin{array}{l}\text { absolute } \\
\text { error/ }(\mu \mathrm{m})\end{array}$} & \multirow{2}{*}{$\begin{array}{l}\text { relative } \\
\text { error } /(\%)\end{array}$} \\
\hline & $\mathrm{R}_{t} /(\mathrm{mm})$ & $a_{f} /(\mathrm{mm} / \mathrm{r})$ & $a_{p} /(\mathrm{mm})$ & $\Delta \theta /\left(^{\circ}\right)$ & & & & \\
\hline 1 & 0.87 & 0.01 & 0.05 & 9 & 0.0472 & 0.0520 & 0.0048 & 10.17 \\
\hline 2 & 0.87 & 0.01 & 0.05 & 8 & 0.0476 & 0.0527 & 0.0051 & 10.71 \\
\hline 3 & 0.50 & 0.03 & 0.03 & 6 & 0.0980 & 0.1130 & 0.0150 & 15.31 \\
\hline 4 & 1.25 & 0.04 & 0.01 & 2 & 0.1420 & 0.1280 & 0.0140 & 9.86 \\
\hline 5 & 0.75 & 0.02 & 0.02 & 4 & 0.0660 & 0.0730 & 0.0070 & 10.61 \\
\hline 6 & 0.87 & 0.01 & 0.04 & 8 & 0.0510 & 0.0570 & 0.0060 & 11.76 \\
\hline
\end{tabular}

\subsection{Establishment of BP neural network pre- diction model}

In this paper, 25 sets of data from the central composite design (excluding one set of duplicate test data) were randomly selected for training the network. Five sets of data and the optimal solution in Section 2.3 were used to test the network. The whole process was performed on Matlab R 2020a. Since there is no standard criterion for determining the hidden layer number, and the number of hidden layer neurons (l) is calculated from equation (1) within a range of 4 to 12 , the 
networks with different numbers of hidden layer neurons were individually tested. Figure 6 shows the effect of the number of neurons in the hidden layer on the network prediction performance, and as seen in Figure 6, the mean square error (MSE) value is smallest when the number of neurons $l$ is 8 . Table 5 shows the relationship between the predicted and actual values of the neural network at $l$ is 8 . The average relative error of prediction is $19.67 \%$ six datasets, which indicates that the prediction ability of the BP neural network in this experiment is average, and the prediction accuracy needs to be improved. This partly due to the prediction accuracy of the BP neural network being greatly affected by connection weights and activation thresholds. The superior weights and thresholds are based on a large amount of sample data. The 25-sample data provided in this paper is relatively small, and the trained weights and thresholds are not necessarily the optimal outcomes, resulting in the poor generali- zation ability of the network model. Currently, the network is usually optimized using relevant algorithms to reduce the dependence of the network on weights and thresholds, increase the network fitting ability, and improve its prediction accuracy.

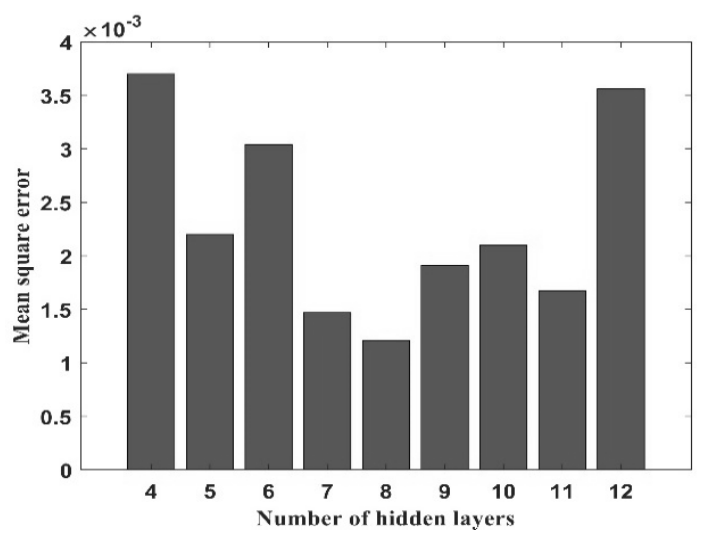

Fig. 6 Effect of the number of neurons in the bidden layer on network performance

Tab. 5 BP neural network prediction results

\begin{tabular}{|c|c|c|c|c|c|c|c|c|}
\hline \multirow{2}{*}{ Serial } & \multicolumn{4}{|c|}{ Parameter } & \multirow{2}{*}{$\begin{array}{c}\text { Predictive } \\
\text { value/ }(\mu \mathrm{m})\end{array}$} & \multirow{2}{*}{$\begin{array}{l}\text { Real va- } \\
\text { lue/( } \mu \mathrm{m})\end{array}$} & \multirow{2}{*}{$\begin{array}{l}\text { Absolute } \\
\text { error/ }(\mu \mathrm{m})\end{array}$} & \multirow{2}{*}{$\begin{array}{c}\text { Relative } \\
\text { error/ }(\%)\end{array}$} \\
\hline & $\mathrm{R}_{\mathrm{t}} /(\mathrm{mm})$ & $\mathrm{a}_{\mathrm{f}} /(\mathrm{mm} / \mathrm{r})$ & $\mathrm{a}_{\mathrm{p}} /(\mathrm{mm})$ & $\Delta \theta /\left(^{\circ}\right)$ & & & & \\
\hline 1 & 0.87 & 0.01 & 0.05 & 9 & 0.0670 & 0.0520 & 0.0150 & 22.39 \\
\hline 2 & 0.87 & 0.01 & 0.05 & 8 & 0.0660 & 0.0527 & 0.0133 & 20.15 \\
\hline 3 & 0.50 & 0.03 & 0.03 & 6 & 0.0940 & 0.1130 & 0.0190 & 20.21 \\
\hline 4 & 1.25 & 0.04 & 0.01 & 2 & 0.1080 & 0.1280 & 0.0200 & 18.52 \\
\hline 5 & 0.75 & 0.02 & 0.02 & 4 & 0.0880 & 0.0730 & 0.0150 & 17.05 \\
\hline 6 & 0.87 & 0.01 & 0.04 & 8 & 0.0710 & 0.0570 & 0.0140 & 19.72 \\
\hline
\end{tabular}

\subsection{Establishment of MEA-BP neural network prediction model}

The initial BP neural network weights and thresholds were optimized using MEA. The number of populations and sample data was set to 200 , the number of both superior and temporary subpopulations was set to 5 , and the superior and temporary subpopulations were required to have the same number of individuals. The parameters of the BP neural network were kept consistent with the above settings. Figures 7 and 8 show the evolutionary process of the victorious and temporary subpopulations in the MEA optimization BP neural network. As can be seen from Figure 7(a), the overall score does not change after expe- riencing four convergences, indicating that the superior subpopulations have all matured. The scores of superior subpopulations 1, 2 and 5 have not changed, indicating that there are no better individuals near these three temporary subpopulations, so no convergence has occurred. From Figure 7(b), it can be seen that the score of temporary subpopulation 3 is higher than that of superior subpopulation 1 after all subpopulations have matured, so an alienation operation is performed to improve the score of the superior subpopulation. For MEA, the higher the score of each subpopulation, the better the optimization performance. After the dissimilation operation is completed, subpopulation 1 in the superior subpopulation will be released, and the system will search again within the whole solution space to form new subpopulations. 

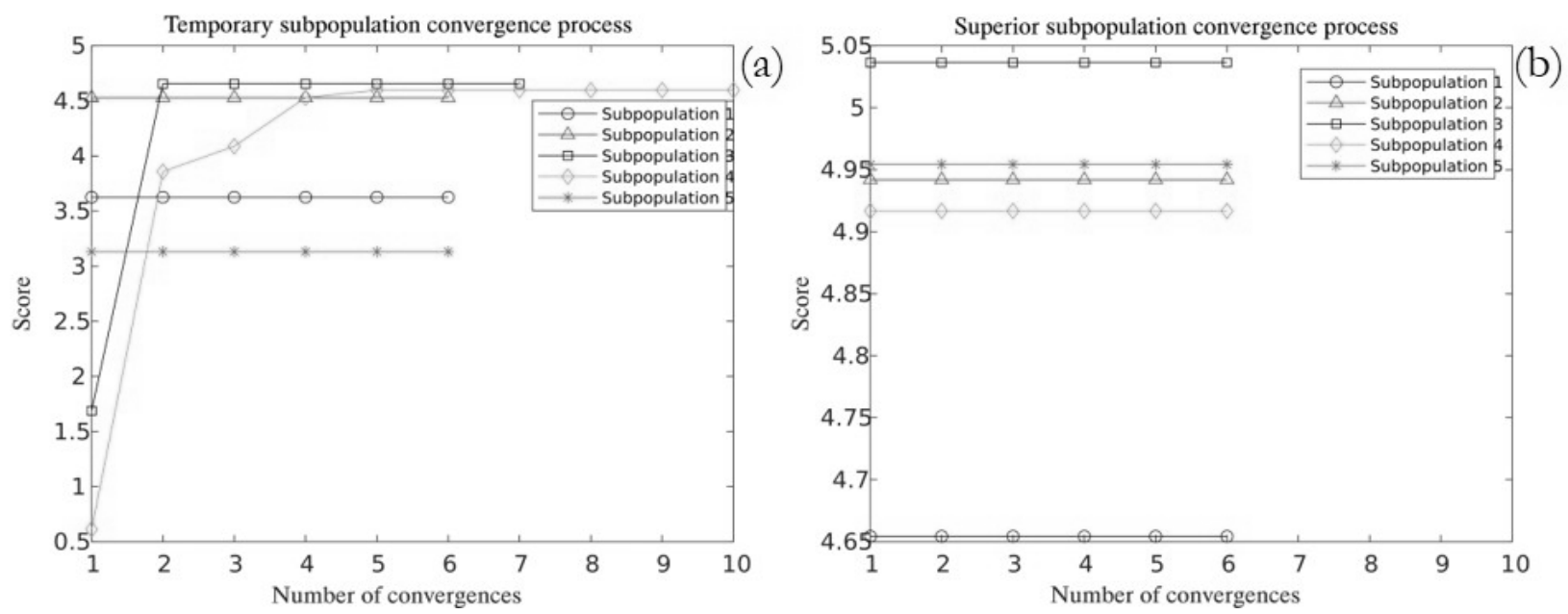

Fig. 7 Subpopulation convergence process before alienation

(a) Temporary subpopulation convergence process before alienation, (b) Superior subpopulation convergence process before alienation

Figures $8(\mathrm{a})$ and $8(\mathrm{~b})$ show the score states of the temporary and superior subpopulations after alienation. From Figure 8(a), it can be seen that the score of the superior subpopulation is not increasing, indicating that all subpopulations have matured. From Figure 8(b), it can be seen that after the dissimilation operation, all temporary subpopulations have lower scores than the superior subpopulation, indicating that each subpopulation has finished training and can be used for optimization training of the BP neural network
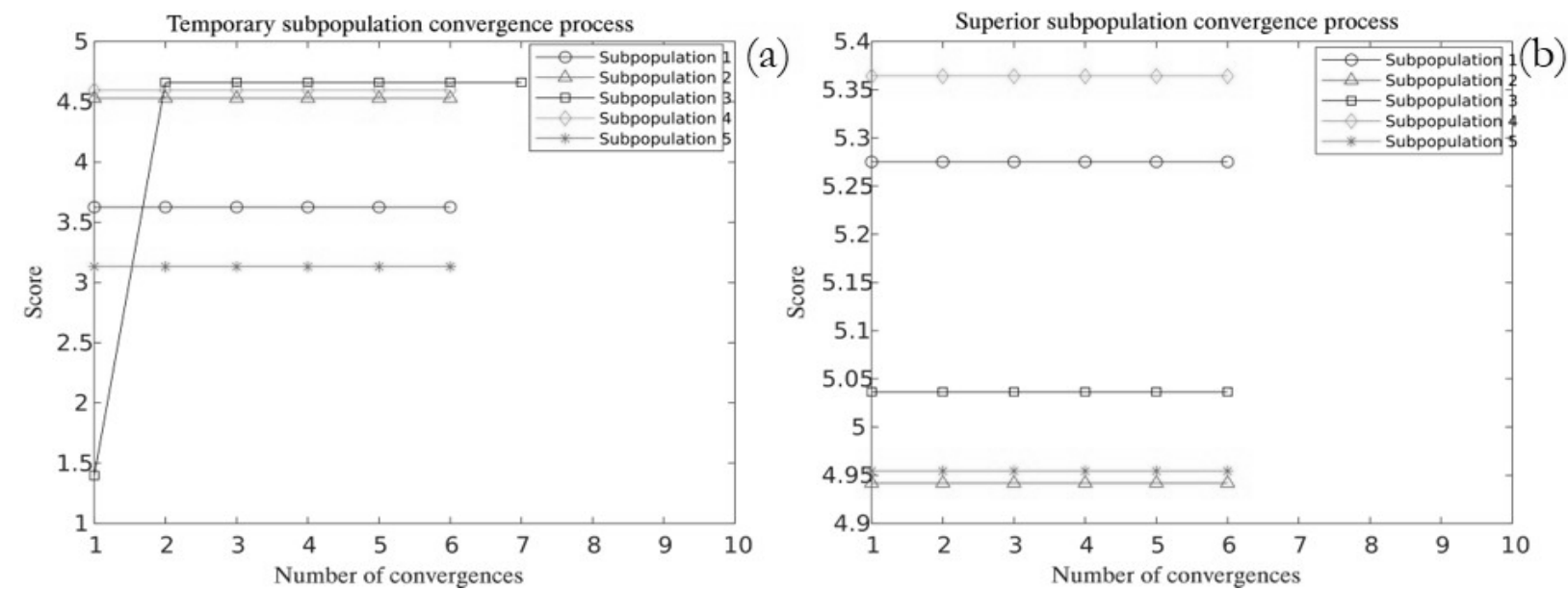

Fig. $\boldsymbol{8}$ Subgroup convergence process after alienation

(a) Temporary subpopulation convergence process after alienation, (b) Superior subpopulation convergence process after alienation

The above six sets of data were substituted into the MEA-BP model. The results are shown in Table 6. The average phase error of the MEA-BP model pre- diction is $5.54 \%$. The data shows that MEA can effectively solve the problem of the BP neural network falling into local optimal solutions and improve the model's prediction accuracy.

Tab. 6MEA-BP neural network prediction results

\begin{tabular}{|c|c|c|c|c|c|c|c|c|}
\hline \multirow{2}{*}{ Serial } & \multicolumn{4}{|c|}{ Parameter } & \multirow{2}{*}{$\begin{array}{c}\text { Predictive } \\
\text { value } /(\mu \mathrm{m})\end{array}$} & \multirow{2}{*}{$\begin{array}{l}\text { Real va- } \\
\text { lue/( } \mu \mathrm{m})\end{array}$} & \multirow{2}{*}{$\begin{array}{l}\text { Absolute er- } \\
\text { ror } /(\mu \mathrm{m})\end{array}$} & \multirow{2}{*}{$\begin{array}{l}\text { Relative } \\
\text { error } /(\%)\end{array}$} \\
\hline & $\mathrm{R}_{t} /(\mathrm{mm})$ & $a_{f} /(\mathrm{mm} / \mathrm{r})$ & $a_{p} /(\mathrm{mm})$ & $\Delta \theta /\left(^{\circ}\right)$ & & & & \\
\hline 1 & 0.87 & 0.01 & 0.05 & 9 & 0.0490 & 0.0520 & 0.0030 & 6.12 \\
\hline 2 & 0.87 & 0.01 & 0.05 & 8 & 0.0543 & 0.0527 & 0.0016 & 2.95 \\
\hline 3 & 0.50 & 0.03 & 0.03 & 6 & 0.1060 & 0.1130 & 0.0070 & 6.60 \\
\hline 4 & 1.25 & 0.04 & 0.01 & 2 & 0.1210 & 0.1280 & 0.0070 & 5.79 \\
\hline 5 & 0.75 & 0.02 & 0.02 & 4 & 0.0770 & 0.0730 & 0.0040 & 5.19 \\
\hline 6 & 0.87 & 0.01 & 0.04 & 8 & 0.0610 & 0.0570 & 0.0040 & 6.56 \\
\hline
\end{tabular}




\subsection{Establishment of MEA-BP neural network prediction model}

In this paper, Mean Square Error (MSE) and the coefficient of determination $\mathrm{R}^{2}$ are used as evaluation indicators. MSE is defined as:

$$
\mathrm{MSE}=\frac{1}{\mathrm{n}} \sum_{\mathrm{i}=1}^{\mathrm{n}}\left(\mathrm{f}_{\mathrm{i}}-\mathrm{y}_{\mathrm{i}}\right)^{2}
$$

Where:

$f_{i}$...Predicted value,

$y_{i} \ldots$..Actual value.
The correlation values of each model are shown in Table 6. It can be seen that the prediction mean square errors of BP, RSM, and MEA-BP gradually decrease, indicating that the prediction accuracy of the model gradually improves; the determination coefficient R2 of MEA-BP is closest to 1, indicating that the network fits better. Therefore, compared with BP and RSM, the MEA-BP model has the highest prediction accuracy.

Tab. 7 Table of prediction parameters of each model

\begin{tabular}{cccc}
\hline Parameter & RSM & BP & MEA-BP \\
\hline MAE & 0.00094 & 0.0011 & 0.00091 \\
$\mathrm{R}^{2}$ & 0.9809 & 0.9254 & 0.9989 \\
\hline
\end{tabular}

The prediction accuracy of the three prediction models was compared and analyzed based on the above six sets of test data, and the results are shown in Figure 9. The prediction accuracy of the MEA-BP model is the highest, with RSM the second highest. The MEA-BP and RSM models meet the error requirements and could be applied in predicting the surface roughness of slow tool servo turning. The BP neural network relative prediction error is more extensive when directly applied to the prediction of surface roughness, displaying a significant prediction error. However, considering the influence of the test data volume on the BP model and the advantages of its simple structure and fast prediction speed, the following finite number of tests can be developed with the help of RSM to increase the test data volume in order to reduce the prediction error of the BP model, and facilitate the application of the BP model in turning tests with low prediction accuracy requirements.

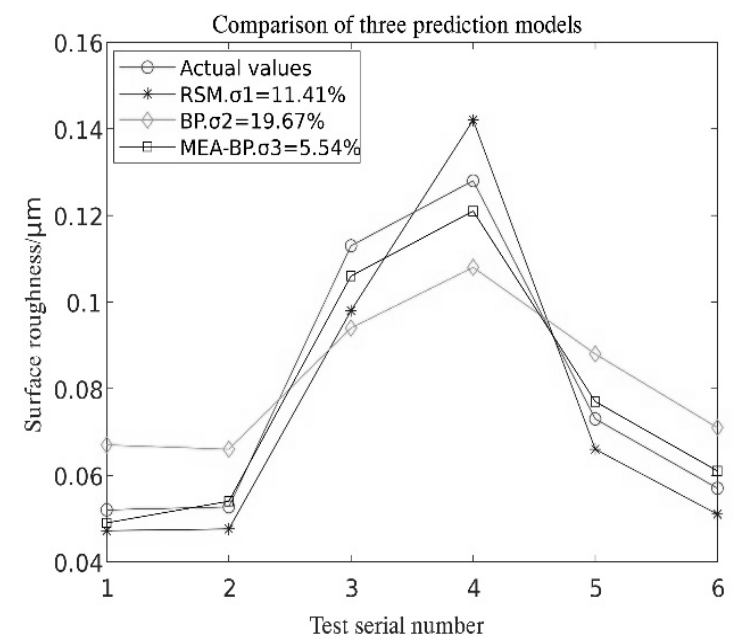

Fig. 9 Effect of the number of neurons in the hidden layer on network performance

\section{Conclusions}

1) The RSM test was carried out via the central composite design method. Four factors: tool radius, feed rate, cutting depth and dispersion angle, were selected as the independent variables. Surface roughness was used as dependent variable to establish the response surface model. The significance of influencing surface roughness was determined by ANOVA, in descending order: tool radius, dispersion angle, feed rate and cutting depth.

2) RSM and BP neural network prediction models were constructed based on the test data. The test data validation showed that the prediction relative error was $11.41 \%$ for the RMS model and $19.67 \%$ for the BP neural network. The prediction and promotional ability of the RSM model was higher than the BP neural network in this experiment.

3) MEA was used to optimize the BP neural network. Test data validation shows that the average relative error of the MEA-BP model $(\sigma 3=5.54 \%)$ is lower than RMS $(\sigma 2=11.41 \%)$ and the BP model $(\sigma 1=19.67 \%)$, with the highest prediction accuracy, indicating that the MEA algorithm has a better optimization effect. The prediction errors of MEA-BP and RSM models are within the acceptable range and can be applied to guide the subsequent slow tool servo turning test.

\section{References}

[1] DONG Q Q (2020). Research on the Key Technology of Slow Tool Servo Turning. Master thesis, Changchun University of Technology, Changchun, China. ISSN

[2] NGUYEN VAN TUONG. (2019). Advanced CAD/CAM Techniques for 5-Axis Machining of Free-Form Surfaces. In: Manufacturing Technology, Vol. 19, NO. 2, pp. 332 - 336. ISSN 
[3] KONG L B, MA Y G, REN M J, et al. (2020). Generation and Characterization of Ultra-precision Compound Freeform Surfaces. In: Science Progress, Vol. 103, NO. 1, pp. 1 - 21. England. ISSN

[4] LI H, LI L K, NAPLES N J, et al. (2017). Micro-optical Fabrication by Ultraprecision Diamond Machining and Precision Molding. In: Frontiers of Mechanical Engineering, Vol. 12, NO. 2, pp. 181-192. China. ISSN

[5] TUONG NGUYEN VAN, NATASA NAPRSTKOVA. (2019). Matlab-based Calculation Method for Partitioning a Free-form Surface into Regions. In: Manufacturing Technology, Vol. 19, NO 3, pp. 518 - 524. ISSN

[6] WANG D F, SUI Y X, YANG H J, et al. (2019). Adaptive Spiral Tool Path Generation for Diamond Turning of Large Aperture Freeform Optics. In: Materials, Vol. 12, NO. 5, pp. 810 - 825. Switzerland. ISSN

[7] KHAGHANI A, CHENG K. (2020). Investigation on Multi-body Dynamics Based Approach to the Toolpath Generation for Ultraprecision Machining of Freeform surfaces. In: Proceedings of the Institution of Mechanical Engineers, Part B: Journal of Engineering Manufacture, Vol. 234, NO. 3, pp. 571 - 583. England. ISSN

[8] LIN Y C, WU K D, SHI W C, et al. (2020). Prediction of Surface Roughness Based on Cutting Parameters and Machining Vibration in End Milling Using Regression Method and Artificial Neural Network. In: Applied Sciences, Vol. 10, NO. 11, pp. 3941 -3963. Basel. ISSN

[9] ALAJMI M S, ALMESHALA M. (2020). Prediction and Optimization of Surface Roughness in a Turning Process Using the ANFIS-QPSO Method. In: Materials, Vol. 13, NO. 13, pp. 2986 - 3009. Switzerland. ISSN

[10] CHEN C, YIN S H, YANG T, et al. (2017). Research on Surface Roughness of Complex Curved Surface in Five-axis Simultaneous Milling. In: Modular Machine Tool and Automatic Processing Technology, Vol. (7), NO. 17, PP. 73-76, 81. China. ISSN

[11] LU J, ZHANG Z K, LIAO X P, et al. (2019). Research on Combined Prediction Model of Cutting Surface Roughness. In: Mechanical Science and Technology, Vol. 38, NO. 9, pp. 14511456. China. ISSN

[12] HSU W Y, LIU Y L, CHENG Y C, et al. (2012). Design, Fabrication, and Metrology of Ultra-precision Optical Free-form Surface for Progressive Addition Lens With B-spline
Description. In: Int J Adv Manuf Tech, Vol. 63, pp. 225-233. Springer. Germany. ISSN

[13] GUO H, KANG M, ZHOU W, et al. (2020). A New Optimal Method of Tool Path Generation for Slow Tool Servo Turning of Complex Surface. In: Manufacturing Technology, Vol. 20, NO. 6 , pp.733 - 747. ISSN

[14] ZHANG X D, FANG F Z, WANG H B, et al. (2009). Ultra-precision Machining of Sinusoidal Surfac-es Using the Cylindrical Coordinate Method. In: J Micromech Microeng, Vol. 19, pp. 10501055. England. ISSN

[15] CAI H B, SHI G Q. (2019). Active Control of Machining Error Slow Tool Servo Turning Path Generation Method. In: Journal of Jilin University (Engineering and Technology Edition), Vol. 49, NO. 4, pp. 1221 - 1227.China. ISSN

[16] SUN Z W, SUET T, ZHANG G Q, et al. (2019). Flexible Fabrication of Micro-optics Arrays with High-aspect-ratio by An Offsettool-servo Diamond Machining System. In: $O p$ tics express, Vol. 27, NO. 7, pp. 9631-9646. United States. ISSN

[17] YI W, ZHAI P, CHEN X Y, et al. (2020). Study on Design and Diamond Turning of Optical Freeform Surface for Progressive Addition Lenses. In: Mathematical Problems in Engineering, Vol. 2020, pp. 1 - 9. England. ISSN

[18] Li C L (2015). Research on Numerical Simulation and Technological Test of Slow Tool Servo Turning of Complicated Curved Surface. Master thesis, Nanjing Agricultural University, Nanjing, China. ISSN

[19] Li C L, KANG M, WANG X S, et al (2014). Surface Roughness Prediction of Slow Tool Servo Turning Based on DEFORM-3D. In: Machine Design and Research, Vol. 30, NO. 4, pp.95 - 99. China. ISSN

[20] XU J, CHI X, CHEN X M, et al (2020). Optimization of Wood Fiber Pulse-Swirl Airflow Drying Process Based on Response Surface Method and BP Neural Network. In: Journal of Northeast Forestry University, Vol. 48, No. 4, pp. 104 - 108. China. ISSN

[21] ZHOU J, BAI Y L, ZHANG X B, et al (2020). Soil Nutrient Evaluation Model Based on MEA-BP Neural Network. In: Chinese Journal of Agricultural Machinery Chemistry, Vol. 41, NO. 2, pp. 231 - 236. China. ISSN

[22] WANG W X, TANG R C, LI C, et al (2018). A BP Neural Network Model Optimized by Mind Evolutionary Algorithm for \& nbsp; Predicting 
the Ocean Wave Heights. In: Ocean Engineering, Vol. 162, pp. 98 - 107. England. ISSN

[23] SHEN Y Y, SHENZ Z, LI J J, et al (2020). Research on Inversion of Penetration Parameters Based on Mind Evolution Algorithm to Optimize BP Neural Network. In: Hydropower Energy Science, Vol. 38, NO. 2, pp. 102 - 121. China. ISSN

[24] HUANG W, CHANG J, SUN Z B. (2019). Prediction of Compressor Characteristic Curve Based on MEA-BP Neural Network. In: Journal of Chongqing University of Technology (Natural Science), Vol. 33, NO. 2, pp. 67 - 74. China. ISSN
[25] ZHANG S, TANG G H, LI K J, et al (2020). Research on Progressive Formability of AZ31B Magnesium Alloy by Oil Bath Heating Based on Response Surface Method. In: Forging \& Stamping Technology, Vol. 45, NO. 5, pp. $81-88$. China. ISSN

[26] WAN J T, WANG Z Y, LIU B H, et al (2019). Optimization of Electrocatalytic Oxidation of Sulfamethoxazole by Response Surface Method and Artificial Neural Network Model. In: Journal of Ocean University of China (Natural Science Edition), Vol. 49, NO. 8, pp. 66 - 74. China. ISSN 